\title{
MINERÍA Y ESTADO: UNA RELACIÓN PERMISIVA
}

\section{MINING AND STATE: A PERMISSIVE RELATIONSHIP}

\author{
Aleida Azamar Alonso*
}

\section{Introducción}

Para mantener el actual nivel de crecimiento económico que demanda el sistema capitalista se ha establecido un modelo productivo basado en la depredación ambiental y social en el que los principales favorecidos son un grupo reducido de empresarios y personas cercanas a las élites políticas (AZAMAR ALONSO, 2018a), los cuales se encuentran ajenos a los costos socioambientales derivados de sus prácticas productivas debido a que su nivel de vida los mantiene alejados de los centros de explotación de riqueza natural (petrolera, minera, forestal, pesquera, acuífera, etc.).

Hasta el momento la indiferencia ante estos efectos negativos socioambientales ha sido impulsada por los limitados y débiles efectos sobre la estructura productiva mundial, pues las afectaciones o desastres ambientales terminan dañando directamente a las comunidades o a pocas ciudades cercanas a los espacios donde se lleva a cabo el proceso de aprovechamiento de la naturaleza. No obstante, en los últimos años se han observado notables cambios en los ecosistemas que generan riesgos para su delicado balance, los ciclos de reproducción de los bienes naturales, poniendo en entre dicho la capacidad para seguir reproduciendo el capital, así como la vida misma, pues los riesgos derivados del cambio climático -tales como los múltiples tornados, huracanes, incendios, deslaves masivos, terremotos y tsunamis, etc.- son, además multimillonariamente costosos de remediar; asimismo, son más perniciosos para los grupos po-

\footnotetext{
* Profesora Investigadora Titular de Tiempo Completo del Departamento de Producción Económica, Universidad Autónoma Metropolitana (Ciudad de México/México). Doctora en Economía Internacional y Desarro-llo. E-mail: gioconda15@gmail.com
} 
blacionales más marginales y casualmente cercanos a las áreas con mayor intensidad productiva (BLANCO et al, 2017).

Por ello resulta fundamental el estudio y análisis de las condiciones normativas que se encargan de analizar el comportamiento de las actividades productivas con mayor impacto socioambiental, una de ellas es: la megaminería. En México la industria minera ha tenido un largo y notable proceso de relación con la población, tanto por el impulso que el Estado le ha dado, como por los intereses económicos alrededor de esta.

En este escenario, la legislación vigente ha tenido diversas modificaciones que le han permitido a dicha actividad ser una de las que mayor relevancia tienen en el mundo, aunque esto no se refleje en el bienestar de la sociedad.

Por lo anterior es que en este trabajo se realiza una revisión histórica de los cambios en el marco normativo minero, específicamente los ocurridos en este siglo para valorar si la legislación actual responde al interés social o por el contrario beneficia a sectores privados. El documento se divide en tres apartados, más las conclusiones. En el primero se establece el marco conceptual de este trabajo y se vincula la relación de los megaproyectos con la regulación nacional del sector minero. En la segunda sección se abordan los aspectos históricos que impulsaron el desarrollo del marco normativo, se presentan sus características, enfoques, además de algunas de las Leyes importan- tes con relación a la minería mexicana. En el tercer apartado se menciona la forma institucional que gobierna a la minería en nuestro país, las estrategias del Estado para potenciar a esta industria, así como la manera que se ha utilizado para cooptar a la población, varias de las cuales también son utilizadas por las empresas. Finalmente, se presentan las conclusiones.

\section{Megaproyectos y minería en México}

En la actualidad la demanda de bienes o servicios en el mundo es cada vez más alta; para poder cubrirla se requieren ingentes cantidades de materias primas para que puedan alimentar los procesos industriales. Es evidente que para cumplir dicho ciclo productivo se deben ampliar las capacidades de explotación de la naturaleza de los proyectos extractivos ${ }^{1}$ comunes migrando hacia los megaproyectos.

Dado que no es posible aplicar un tamaño común o estándar para este tipo de actividades por las variaciones de los recursos que se van a obtener, generalmente se consideran criterios económicos para calificar un megaproyecto como tal. De acuerdo con Abedrapo (2011) estos son los que superan la barrera de los 1,000 millones de dólares en inversión. No obstante, este tipo de valoración puramente económica sigue siendo limitada, pues no considera las condiciones socioeconómicas de las naciones subdesarrolladas (donde se llevan a cabo

1. En este trabajo el extractivismo se refiere a todos aquellos procesos de extracción de materias primas del lecho marítimo, subsuelo y de la superficie a través de métodos intensivos basados en la apropiación y el despojo territorial. 
con frecuencia este tipo de actividades), por lo cual los megaproyectos se entenderán, en este trabajo, como aquellas actividades cuya dimensión (física, así como de capital y requerimiento de personal) superen la capacidad de carga territorial (demanda máxima de recursos que un área puede proveer a una población determinada) y que ponga en riesgo irreversible la sustentabilidad social, ambiental, económica y cultural, presente y futura, del lugar donde se realizan.

En este escenario, los países cuyas capacidades tecnológicas sean débiles e insuficientes para producir bienes complejos se verán limitados a cubrir las exigencias de materias primas externas. Mandel (1971, p. 7) lo señala de la siguiente forma:

Los países subdesarrollados fueron incluidos en el mercado mundial por iniciativa del capital occidental. En la mayoría de los casos éste carecía de la posibilidad (demanda local insuficiente) y del interés (voluntad de evitar la concurrencia en relación a su propia industria metropolitana), de crear en ellos una industria manufacturera moderna. Pero, de cualquier forma, los países subdesarrollados debían producir mercancías para un mercado esencialmente exterior. Era lógico, por tanto, que las inversiones realizadas en ellos fueran fundamentalmente complementarias de la industria capitalista occidental y centrada en la producción de materias primeras minerales o vegetales y en la producción de alimentos.

Es decir, en las naciones cuyo capitalismo se encuentra menos desarrollado ${ }^{2}$ se fomentan dependencias estructurales a los mercados externos a través del comercio e inversión productiva, esto se logra por medio de la implementación de mecanismos de explotación intensiva territorial (megaproyectos), cuyo único fin es fomentar la operación de inversiones rentables (LUXEMBURG0, 1967), que a su vez fortalezcan la provisión de materias primas a los países desarrollados (AZAMAR ALONSO, 2018a).

Con la finalidad de lograr que se lleven a cabo este tipo de actividades se han implementado múltiples cambios legislativos en las Constituciones de las naciones en vías de desarrollo (principalmente en América Latina y África) y de esta forma se ha facilitado la apertura al capital extranjero para que se apropien de los recursos naturales. Dichos cambios han sido resultado de procesos internos o de imposiciones político-económicas (AZAMAR ALONSO, 2017 y 2018a), pues resulta evidente que en el largo plazo generarán más riesgos que

2. Mandel (1971, p. 7) considera que la formación proletaria constituye el origen y forma del capitalismo, explicándolo de la siguiente manera: "En Europa Occidental este proceso condujo a la expulsión de los campesinos de sus tierras, a la miseria campesina, a la proletarización masiva del campesinado, por una parte, pero, por otra, a la formación del capital industrial, con la aparición de un número creciente de empresas industriales. En los países subdesarrollados sólo la primera parte del proceso se ha reproducido enteramente; la segunda sólo se repite de manera parcial y totalmente insuficiente". 
beneficios los megaproyectos extractivos.

Se debe considerar que en las regiones donde se realizan los megaproyectos, el Estado se posiciona a favor de estos y respalda su accionar, aunque esto signifique una agresión directa a la sociedad, ya que obliga a las comunidades a migrar hacia espacios que no estén amenazados por este tipo de actividades (TETREAULT, 2019). Por otra parte, para la mayoría de las naciones de América Latina y también para el caso mexicano, una notable mayoría de megaproyectos se realizan por parte de empresas extranjeras que son las principales inversoras en este sector.

En México, existen dos tipos de compañías, las primeras son nacionales con gran tamaño e importancia -también denominadas translatinas, ya que operan en otras zonas del mundo, principalmente de América Latina-; las segundas son internacionales -denominadas transnacionales- con una gran cantidad de proyectos activos, pues son responsables de más de la mitad de los megaproyectos ${ }^{3}$ activos en el país.

En el conjunto de la región latinoamericana el incremento en la cantidad y tamaño de los proyectos extractivos activos se ha traducido en una invasión del territorio, sobre todo en el caso de la imposición de proyectos productivos mineros ajenos a las sociedades cercanas a donde se encuentran dichos proyectos, y en una clara carencia de control efectivo sobre estas actividades, ya que se han incrementado los conflictos socioambientales como consecuencia de la ausencia de normas lo suficientemente fuertes para controlar dichos proyectos.

Además, la ausencia de una industria minera por parte del Estado no se ha traducido en ahorro e inversión para la nación, pues los efectos ambientales provocados por la minería son tan graves -destrucción territorial, agotamiento o envenenamiento de mantos acuíferos, contaminación del subsuelo, etc. - que al final de su actividad son remediados por el Estado debido a que algunos se presentan tiempo después que terminan las operaciones y otros son persistentes (el envenenamiento de agua y de la tierra), ya que se mantienen aun cuando ya no está activa la operación minera, entre otras cosas.

Por otra parte, la tendencia extractivista tiende a la reprimarización de las comunidades y en algunos casos también de los países en los que se manifiesta, dificultando con ello la creación de un mayor abanico de oportunidades productivas o actividades de producción agrícola con mayor nivel de especialización que puedan proveer otras formas de ingresos con diferente tipo de valor agregado menos propenso a las presiones externas.

Las condiciones modernas de los mercados de materias primas y la competencia internacional han forzado a México y a la mayoría de las naciones latinoamericanas a disminuir sus exigencias normativas para la creación y operación de actividades de explotación de los bienes naturales (principalmente de la minería).

3. Dado que este trabajo se centra en la minería los datos comentados a partir de este punto se referirán a esta industria, a menos que se comente lo contrario. 
La participación del Estado es clave para la consolidación de los nuevos megaproyectos extractivos en la región, pues, coaccionados por las desventajas que les caracterizan, por la presión de organismos internacionales y de otros países acreedores de la deuda externa que mantienen, así como por el interés de financiar sus propias agendas políticas, promueven condiciones óptimas para la inversión privada en las actividades de explotación socioambiental. Dichas situaciones han creado múltiples efectos negativos en la dimensión social, económica, ambiental y cultural de estos países.

La falta de una propuesta de política integral que regule dichas actividades en busca del beneficio social para disminuir el daño para la sociedad y la naturaleza ha generado un ambiente de tensión entre el gobierno, la población y las empresas extractivas. De ahí, la necesidad de abordar los aspectos referentes a la normatividad y su aplicación. Asimismo, vale la pena resaltar que en las últimas décadas del siglo XX y hasta la actualidad, las compañías mineras en el territorio mexicano recibieron una notable cantidad de beneficios para poder desarrollarse. De esta forma, aunque las empresas extranjeras han tenido un mayor nivel de presencia en el país, la evolución productiva de algunas compañías nacionales es destacable por su crecimiento económico e importancia internacional, aunque con un diluido impacto en el bienestar económico local, lo que es obviado por la población debido a la creación de formas de cooptación y manipulación social.

Considerando lo comentado, en el siguiente apartado se comentará cómo la estructura normativa que rige el desarrollo de la minería y los megaproyectos en este sector se ha centrado en fomentar los as- pectos que benefician a la industria, pues corresponde históricamente con la configuración del capitalismo que se desarrolla en esta nación.

\section{Normatividad minera mexicana ante el interés economicista}

La década de los noventa fue para México el inicio de un largo proceso de restructuración en los marcos jurídicos internos con la finalidad de redefinir las tareas gubernamentales respecto a la regulación de las condiciones de producción en las actividades extractivas, particularmente para la minería y el petróleo; lo anterior ha propiciado que el Estado se vincule de forma servicial con el sector empresarial, expresándolo a través de esquemas normativos laxos.

Además, esto ha conducido al país hacia una sociedad dirigida por intereses privados, una "hegemonía empresarial" como lo señala Palacio (2011, p. 93) que tiende a exentar de sus obligaciones a las grandes compañías, otorgándoles derechos superiores a los de otros actores del mismo ramo (CÁRDENAS GRACIA, 2013). De esta forma se impulsó a la minería a través de una serie de estrategias de apropiación y despojo (AZAMAR ALONSO, 2018a; LÓPEZ; VÉRTIZ, 2017; OLIVERA VILLA; DE LA FUENTE, 2018) que casi treinta años después continúan siendo la plataforma sobre la cual crece día a día este tipo de extractivismo.

Durante la década de los noventa del siglo XX, los megaproyectos mineros de capital extranjero fortalecieron su presencia en el territorio mexicano, desde entonces las compañías en este sector se han servido de las reestructuraciones generadas a partir de la implementación del neoliberalismo 
en nuestro país. Un ejemplo es el de aquellas con capital canadiense, las cuales han acaparo la exploración de metales preciosos, amparándose en el derecho preferencial que les otorga el artículo $4^{\circ}$ de la Ley minera, el cual establece que los titulares que ya cuenten con una concesión minera sobre determinado mineral o sustancia tendrán preferencia sobre concesionarios en la asignación de nuevas concesiones. Por ello “desde 1991, prácticamente todas las empresas canadienses importantes del sector tienen intereses en el país, y su actividad se ha incrementado desde 1992 y 1993 gracias en buena medida a los cambios introducidos por el régimen salinista en la Ley Minera” (BURNES, 2006, p. 296).

Asimismo, desde 1990 y hasta la actualidad se construyó un aparato jurídico complaciente fincado en la concentración oligopólica de la industria, como lo señala Burnes (2006, p. 263) al referenciar las condiciones del universo empresarial local: “en 1992 cinco empresas -Industrial Minera México, Peñoles, Corporación Industrial San Luis, Frisco y Autlán- concentraban el 80 por ciento de la producción minera nacional".

Resulta evidente que este proceso de aglutinamiento -territorial y productivoera incentivado por la debilidad legislativa entorno a esta práctica extractiva, lo que fue acentuado por las múltiples reformas constitucionales, así como por un replanteamiento a las leyes en vigor: minera, de inversión, ambiental, etc., las cuales se realizaron desde la década de los noventa con la intención de insertar al país en la reciente dinámica globalizadora.

La voluntad política que facilitó todo el proceso ya comentado fue la del expresidente Carlos Salinas de Gortari (1988-
1994), quien sentó las bases para que el sector minero se expandiera y fortaleciera debido al proceso de reestructuración -básicamente transformación de las tareas de regulación de las condiciones de producción- apoyado por el Banco Mundial bajo un amplio programa de modernización de esta industria.

A partir de 1994 se inició un nuevo ciclo de crecimiento para los megaproyectos mineros impulsado por el esquema de monopolización, invisibilización del Estado como regulador y fortalecimiento de la figura empresarial. Las estrategias del Proyecto Nacional de Modernización de la Minería 1990-1994, fueron, según la Cámara Minera de México (CAMIMEX), las acciones gubernamentales que permitieron aumentar las inversiones y reducir los costos de operación de los productores mineros (BURNES, 2006).

De toda la política de desregulación, la promulgación de la Ley minera de 1992 es el marco jurídico con mayor influencia para la sociedad mexicana en lo que respecta al sector minero. Esta Ley complementó su eficacia para beneficio de la industria con la firma del Tratado de Libre Comercio de América del Norte (TLCAN) en 1994 y con las consiguientes reformas constitucionales acompañadas de la modificación de ciertas Leyes Generales encargadas de regular la conducta empresarial en México (DELGADO RAMOS, 2012). En términos generales, el resultado de la flexibilización del marco jurídico dio pie a la entrada masiva de capitales extranjeros, al aprovechamiento prácticamente ilimitado de suelo, agua y energía, además del aumento de la sobreexplotación laboral. 


\subsection{Ley minera de 1992}

El marco legal que rige las prácticas del extractivismo minero en México -exceptuando a los hidrocarburos y a los materiales radioactivos- es la Ley minera. Esta Ley, promulgada el 26 de junio de 1992, no deja lugar a dudas sobre el apoyo incondicional del Estado mexicano para garantizar la profundización de la sobreexplotación de la naturaleza para la reproducción del capital global.

Dicha Ley declara a la actividad minera de utilidad pública, por lo que será preferente sobre cualquier otro uso o aprovechamiento del terreno donde se encuentren los minerales. A través de esta estructura jurídica, se previó que, durante la administración federal de Salinas de Gortari, la inversión sería cuatro veces mayor que la inversión captada durante los cinco años anteriores (BURNES, 2006).

Además, durante la década de los noventa, el gobierno federal encabezado por Ernesto Zedillo estableció que la minería requería de capital de riesgo para la exploración y de altas inversiones para la fase de explotación, por lo que era necesario permitir la entrada de capital extranjero a esas actividades. Ese argumento oficial no era más que una forma sutil de abrir camino legal a las transnacionales para que extendieran su dominio a esa parte de la economía (LÓPEZ BÁRCENAS; ESLAVA GALICIA, 2011), con lo cual también se beneficiaron las grandes compañías mineras mexicanas.

Antes de la Ley de 1992, las empresas mineras debían informar al gobierno mexicano el tipo de mineral que buscaban y esperaban encontrar durante la etapa de explotación. De igual manera, una vez encontrado el recurso debían confirmar el tipo de material que explotarían, en cambio con la Ley de 1992 esta obligación básica despareció, ya que el artículo quince de la Ley minera expresa que "las concesiones mineras conferirán derechos sobre todos los minerales o sustancias sujetos a la aplicación de esta ley" (LEY MINERA, 2018).

Por lo que, una vez asignada la concesión de exploración la empresa es libre de hacer uso del suelo y subsuelo como mejor convenga a sus intereses sin tener que informar a ninguna institución gubernamental sobre sus actividades. Cabe resaltar que el beneficio de no informar sobre la explotación se convierte en un mecanismo adicional con el que las empresas pueden especular en la bolsa de valores, pues al no estar obligadas a reportar datos exactos sobre el tipo de bienes obtenidos se presta a que informen solamente los factores que tengan impactos positivos en su cotización en la bolsa de valores a nivel mundial (DE LA FUENTE; OLIVERA VILLA, 2017).

Por otro lado, en el año 2006, el Congreso mexicano realizó modificaciones al artículo 27 constitucional, así como a la Ley Minera vigente sobre lo concerniente a las capacidades de uso de recursos para que los concesionarios mineros pudieran aprovechar el gas asociado a los yacimientos de carbón mineral (LÓPEZ BÁRCENAS; ESLAVA GALICIA, 2011), utilizando como argumento que la imposibilidad de recuperar el gas que se genera en el proceso de aprovechamiento había propiciado la explosión de la mina de Pasta de Conchos, en Coahuila. Es decir, justificaron la flexibilización legal con las empresas del sector minero a partir del accidente de la empresa Grupo México (dueña de la concesión) que provocó víctimas mortales en el año 2006.

Adicionalmente a las capacidades extendidas que tienen las compañías para apro- 
vechar sin muchas restricciones operativas sus concesiones, también se debe mencionar el drástico incremento en el tiempo de explotación de las minas. En la actualidad los permisos que el gobierno federal entrega a las empresas del sector a través de la Secretaría de Economía tienen una duración de cincuenta años con posibilidad de renovarse otros cincuenta años más, lo único que se necesita es que la compañía interesada informe con antelación al término de la primera etapa; hasta ahora esta es la única condición para la renovación sin consideración de otra exigencia. Ante esta flexibilidad, es posible afirmar que las concesiones mineras en México tienen, prácticamente, una duración de cien años, en los cuáles las empresas ocupantes no están obligadas a informar el tipo o los tipos de minerales explotados.

Además de las ventajas anteriores, la Ley minera no impone una restricción en el número de concesiones que una empresa puede obtener en el país, por lo que este sector es atractivo para la inversión extranjera o nacional.

El motivo para que las concesiones sean tan largas responde más al mercado especulativo que al ejercicio extractivista per se. $\mathrm{Y}$ es que se permite a los titulares de las concesiones retenerlas sin explotarlas por una gran cantidad de tiempo ${ }^{4}$ para que se puedan aprovechar las condiciones de mercado favorables que garanticen las inversiones de la explotación, o bien, traspasar la concesión ${ }^{5}$.

\subsection{Ley de Inversión Extranjera ante la participación minera en México}

En cuanto a los aspectos de promoción y fomento externo de esta actividad se encuentra la Ley de Inversión Extranjera de 1993, cuyo marco legal permitió la participación de capitales foráneos en cualquier nivel o proporción de sociedades mexicanas (GARIBAY, 2010).

Esta Ley es parte de las estrategias jurídicas que el gobierno mexicano puso en marcha desde la década de los noventa para atraer inversiones de capital al sector, lo que definitivamente determina la composición de la industria y con ello la profundización de la transferencia ecológica que los megaproyectos mineros implican en la actualidad. Sin embargo, es preciso resaltar que tanto las inversiones extranjeras como las de origen mexicano, han practicado el extractivismo intenso bajo la misma lógica depredadora.

\footnotetext{
4. Dicho periodo de inactividad quedaría relativamente atajado mediante el derecho sobre concesiones no productivas llamado derecho adicional, que impone una cuota a quienes no produzcan durante un periodo continuo de dos años. No obstante, dado que los costos de renta por hectárea en México son tan bajos, es posible asumir que no implica una gran pérdida para el empresario pagar dicho derecho ante la posibilidad de verse beneficiado con un mayor ingreso a futuro.

5. Al respecto se puede señalar que "la titularidad de las concesiones, sobre todo las de explotación y beneficio, también permiten no explotar el mineral que amparan, sino retenerlas para que otros no lo hagan. De esa manera podrían explotarlas o transmitirlas cuando el material suba de precio" (BÁRCENAS; ESLAVA, 2011, p. 36).
} 
Vale la pena señalar que la orientación de la reforma a esta ley está orientada a permitir la formación de sociedades mercantiles en la que los extranjeros serán socios mayoritarios o absolutos, por lo que pueden invertir libremente en gran parte del país sin necesidad de contar con participación nacional. Esto ha generado una vocación principalmente exportadora, pues los núcleos operativos de estas compañías se encuentran ubicados en otros países, lo que debilita el mercado interno y atenta contra la soberanía territorial al facilitar grandes cantidades de superficie para su aprovechamiento sin garantizar beneficio adicional a la propia inversión operativa.

\subsection{Ley de Responsabilidad Ambiental ante la minería}

A pesar de que la Ley minera es la norma más importante que regula esta actividad en el país, existen otras Leyes que más allá de normar las prácticas corporativas han servido al gobierno mexicano para atraer inversiones. Paradójicamente una de estas leyes es la Ley de Responsabilidad Ambiental, un marco que contempla reparación de daños, multas, responsabilidad a socios y representantes de empresas, pero que dado el enorme cuidado que el lobby minero ha tenido con esta Ley, hoy sólo es un documento administrativo.

$\mathrm{Al}$ respecto se puede señalar que la CAMIMEX informó en el 2012 que la Ley de Responsabilidad Ambiental no debería perjudicar al sector minero como resultado de las modificaciones sugeridas por este organismo durante el año 2011. Esta institución, junto a la Confederación de Cámaras Industriales (CONCAMIN) y otras Cámaras empresariales, cabildearon para modificar esta ley argumentando que la moderación afectaría la competitividad de la minería mexicana en el mundo (CAMIMEX, 2012).

La regulación ambiental debe entenderse en un contexto de procuración del bienestar humano, aislado del interés economicista. Es decir, se debería tratar de una normatividad que atiende al beneficio social y en esta se descubre el verdadero objetivo de gobernanza del Estado.

\subsection{El sector minero y la Ley General de Equilibrio Ecológico y Protección al Ambiente}

Otra de las leyes que reglamenta los aspectos ambientales de la actividad minera es la Ley General de Equilibrio Ecológico y Protección al Ambiente (LGEEPA) a través de la Secretaría de Medio Ambiente y Recursos Naturales (SEMARNAT) y por medio de la Evaluación de Impacto Ambiental (EIA). Esta institución se encarga de revisar los componentes del proyecto y sus posibles impactos.

La EIA incluye la presentación de Estudios de Riesgo, Informes de Riesgo, Informes Preventivos y la Manifestación de Impacto Ambiental (MIA). La MIA es importante porque en ella se incluyen las características del contexto sociocultural de la zona de impacto. No obstante, la presentación y el análisis del aspecto sociocultural no son de carácter obligatorio, sino que, según la autoridad, el objetivo es orientar sobre este aspecto, con lo cual la elección de los estudios sociales queda totalmente a criterio de la empresa, básicamente de la consultora que realiza la MIA.

Por lo que, la MIA no es, como sería legítimo suponer, un sistema de reglas o una norma de evaluación, en realidad quien decide sobre las fuentes, la metodología y la interpretación de los resultados es la 
empresa interesada en el proyecto minero y no la autoridad ambiental del gobierno mexicano.

Un caso que se puede mencionar son las políticas de regulación minera en el estado de Baja California Sur. En 2011 los legisladores de esa entidad prohibieron a los gobiernos estatal y municipal otorgar permisos para emprendimientos mineros que se fueran a realizar con el método de tajo a cielo abierto. Sin embargo, en el mismo año, a expreso cabildeo de la CAMIMEX, dicha limitación quedó suspendida.

CAMIMEX publicó en su Informe (2012) que logró convencer a las autoridades y legisladores de Baja California Sur de que la prohibición de minería a cielo abierto sería anticonstitucional y tendría consecuencias negativas para el desarrollo socioeconómico de la entidad, ya que inhibiría la inversión para fuentes de empleo, infraestructura y beneficios a comunidades.

Considerando que las compañias buscan incrementar principalmente sus capacidades de generar ganancias económicas sin importar si esto pone en riesgo a los trabajadores, a la población o al ambiente (como se mencionó con el ejemplo de Baja California Sur), parece que no queda claro cuáles son los beneficios que las comunidades reciben al permitir la llegada de un megaemprendimiento minero en sus territorios. Sin embargo, lo que sí queda de manifiesto en esta situación, es el enorme poder del sector para modificar cualquier ordenamiento legal que intente contener su expansión y los enormes impactos ambientales de sus métodos extractivos.

\section{Institucionalismo minero mexicano}

Después del rediseño del marco jurídico oligárquico que comenzó en la década de los noventa, durante el periodo subsecuente continuaron las adaptaciones del aparato gubernamental para consolidar a la industria minera. La primera década del siglo XXI terminó por organizar todas las agencias gubernamentales de las que actualmente se sirven las megaempresas mineras en México.

De esta manera se estableció un mapa institucional profundamente opaco y caracterizado por la falta de mecanismos para que se puedan cumplir las reglamentaciones vigentes. Algunos de estos organismos se mencionan en el siguiente cuadro: 
Cuadro 1. Estructura institucional minera en México

\begin{tabular}{|c|c|}
\hline Organismo & Función \\
\hline $\begin{array}{l}\text { Coordinación Gen- } \\
\text { eral de Minería } \\
\text { (CGM) }\end{array}$ & $\begin{array}{l}\text { Esta Coordinación depende directamente de la Secretaria de Economía. Es la institución } \\
\text { encargada de aplicar las disposiciones legales para el sector minero, de manera que } \\
\text { quede asegurada la libre competencia entre los particulares tanto en el área de explor- } \\
\text { ación como de explotación. Su objetivo es ofrecer seguridad jurídica a todos los inver- } \\
\text { sionistas de la industria. }\end{array}$ \\
\hline $\begin{array}{l}\text { Dirección General } \\
\text { de Minas } \\
\text { (DGM) }\end{array}$ & $\begin{array}{l}\text { Esta Dirección garantiza la tramitación de todos los asuntos administrativos relacionados } \\
\text { con el sector minero. Su marco legal es la Ley minera y su Reglamento. A decir del gobi- } \\
\text { erno mexicano, la DGM otorga seguridad jurídica a las resoluciones que derivan de la Ley } \\
\text { Minera. }\end{array}$ \\
\hline $\begin{array}{l}\text { Dirección General } \\
\text { de Promoción de } \\
\text { Minas (DGPM) }\end{array}$ & $\begin{array}{l}\text { Es la institución encargada de promocionar la competitividad y la inversión en el sector } \\
\text { minero, vigilando que este cuente con las políticas públicas adecuadas para el fortaleci- } \\
\text { miento de la minería. Entre sus tareas se encuentran propiciar todas las facilidades para } \\
\text { la inversión e identificar nuevas oportunidades de negocios. }\end{array}$ \\
\hline $\begin{array}{l}\text { Fideicomiso de } \\
\text { Fomento Minero } \\
\text { (FFM) }\end{array}$ & $\begin{array}{l}\text { Entre sus propósitos está el financiamiento a personas físicas o morales interesadas en } \\
\text { invertir en la industria minera, también brinda apoyos a la inversión mediante capacit- } \\
\text { ación y asistencia técnica. El FFM puede otorgar financiamiento hasta por } 5 \text { millones de } \\
\text { dólares o se equivalente en pesos mexicanos. }\end{array}$ \\
\hline $\begin{array}{l}\text { Servicio Geológico } \\
\text { Mexicano } \\
\text { (SGM) }\end{array}$ & $\begin{array}{l}\text { Este organismo es indispensable para el sector minero ya que le provee de insumos } \\
\text { indispensables para el aprovechamiento de los recursos minerales. Según el gobierno } \\
\text { mexicano, el SGM fomenta la inversión, ofreciendo información técnica por cada entidad } \\
\text { del país. }\end{array}$ \\
\hline $\begin{array}{l}\text { Procuraduría } \\
\text { Agraria } \\
\text { (PA) }\end{array}$ & $\begin{array}{l}\text { Oficialmente, la PA es la institución del gobierno federal encargada de "asesorar a los } \\
\text { sujetos agrarios en la realización de los contratos, convenios o cualquier otro acto ju- } \\
\text { rídico que celebren entre sí o con terceros en materia agraria; proponer la política nacio- } \\
\text { nal para garantizar y defender los derechos agrarios, así como la relativa a los derechos } \\
\text { humanos que pudieran incidir en materia agraria" (GARIBAY, 2010, p. 170). No obstante, } \\
\text { en materia minera, cumple precisamente con la función contraria, al asesorar a las com- } \\
\text { pañías mineras en contra de los sujetos agrarios del país. }\end{array}$ \\
\hline
\end{tabular}

Fuente: elaboración propia

En el cuadro 1 se realiza una breve revisión de algunos de los actores institucionales con mayor relevancia dentro del proceso que se refiere específicamente a la operatividad de la actividad minera. Adicionalmente a estos organismos existen otras nueve instituciones que se vinculan a la cuestión administrativa en distintos rubros (véase esquema 1). 
Esquema 1. Dependencias federales para la regulación administrativa minera

\section{Secretaria de Economia}

\section{-Concesiones, inversión y registro empresarial}

\section{Secretaria de Hacienda y Crédito Público}

\section{-Aspectos tributarios}

\section{Secretaria de Relaciones Exteriores}

\section{- Constimrión de empresas}

\section{Secretaria del Medio Ambiente y Recursos Naturales}

\section{-Regulación ambiental}

\section{Secretaria de Desarrollo Agrario Territorial y Urbano}

\section{-Tenencia de la tiena}

\section{Secretaria de Energia}

\section{-Regulación operatira en el manejo de combustiples}

Secretaria del Trabajo y Prevision Social

\section{-Protección a los derechos de los trabajaines}

\section{Secretaria de la Defensa Nacional}

\section{-Manejo de explosivos parala operación}

\section{Instituto Mexicano de la Seguridad Social}

\section{-Derechos de salnd}

Fuente: elaboración propia con datos de la Secretaría de Economía (2013).

Aunque es evidente que se requieren diferentes niveles de autorización, revisión y monitoreo para una actividad como la megaminería que presenta múltiples tipos de riesgos, también queda claro que falta una figura central que audite, controle y centralice todos los elementos estadísticos (permisos, etapa de trabajo y tipo de impuestos que tributa, entre otros), para fortalecer la forma en que se puede analizar y controlar la explotación territorial en el país.

Por otro lado, durante el periodo de gobierno que encabezó el expresidente Enrique Peña Nieto (2012-2018), la única modificación relevante en el esquema operativo institucional fue la creación de la Subsecretaría Minera $(\mathrm{SM})^{6}$, la cual es una institución que debería ser sucesora de la 
Coordinación General de Minería (CGM). No obstante, hasta el momento todos los documentos oficiales del sector siguen haciendo alusión a la CGM en vez de a la SM. Esta situación muestra parte de la debilidad institucional del Estado para controlar a nivel operativo la actividad minera.

Los planes de gobierno a futuro (20182024) para el ordenamiento administrativo no se han precisado $^{7}$, por lo que se puede estimar que probablemente no habrá cambios drásticos en la forma en cómo se ha operado hasta ahora en la minería. Esto puede significar que las prioridades del Estado se van a centrar en generar un mayor nivel de coordinación y comunicación entre las instituciones públicas, ello es una aseveración basada en los principales problemas que atañen a este sector.

Las características de la mencionada arquitectura giran en torno a su elevada filosofía tecnocrática, cuyo objetivo es fomentar la explotación intensiva privada con fines economicistas y de inserción en las cadenas globales de valor con la intención de mejorar la atracción del país para la inversión foránea.

Este aspecto se retoma del plan de gobierno del actual presidente Andrés Manuel López Obrador, quien ha señalado en varias ocasiones que la minería es una actividad relevante y fundamental. Además de que debe integrarse y potenciarse su importancia para el desarrollo nacional. Cuestión que resulta continuista con la línea de sus antecesores. Aunque vale la pena mencionar que se están incorporando algunas limitantes para este sector mediante la posible modificación de la Ley Minera.

Los cambios a dicha Ley se refieren específicamente a aspectos que intentan dotar de capacidades a las instituciones como la Secretaría de Economía y al Servicio Geológico Mexicano en la imposición de penalizaciones legislativas hacia las empresas que incumplan con las leyes nacionales; además, se pretende buscar un mayor consenso con las comunidades (indígenas y campesinas) que se ven afectadas por este tipo de actividades, así como la prohibición de la práctica extractiva en Áreas Naturales Protegidas (ANP) ${ }^{8}$.

anterior son mecanismos de transferencia de recursos para el Estado y las comunidades donde se alojan los proyectos mineros (AZAMAR, 2018a).

7. En marzo de 2019 el presidente de la República señaló en conferencia de prensa que no se otorgarían más concesiones mineras durante su sexenio. No obstante, esto no se ha publicado en ningún medio oficial del gobierno, tampoco ha sido corroborado por ninguna otra autoridad. Además, esto se ha puesto en duda, pues durante el mes de febrero se otorgaron nuevos permisos de concesión minera para más megaproyectos. 8. En marzo de este año (2019), el presidente de la República mexicana anunció la cancelación del proyecto minero "Los Cardones" ubicado en Baja California Sur. La empresa que participa en este proyecto es Desarrollo Zapal, subsidiaria de Invecture Group, la cual también tiene otros proyectos que se dedican a esta industria en el país. Este proyecto ha tenido varios conflictos con diferentes sectores de la sociedad debido a que se ha manifestado que de realizarse presentaría uso intensivo de agua en una zona en donde se carece de este bien. 
Aunque estas reformas (autonomía y fortalecimiento institucional, así como vinculación con la sociedad y reforzamiento en la protección a las áreas naturales) son tibias por la falta de enfoque y señalamiento en los elementos negativos clave que genera esta industria, lo cierto es que estas posibles modificaciones han despertado un profundo rechazo del sector empresarial minero argumentado que afectarían gravemente a la industria.

Pero, esto es incierto, pues como se ha mencionado, parte de la forma en que la minería ha crecido es mediante la táctica de apropiación y despojo, lo que se ha fortalecido con la vinculación Estado-empresa en la que se han llevado a cabo múltiples reformas que han favorecido a privados con posiciones ventajosas -como la declaración de que sus actividades productivas son de utilidad pública- frente a la población en general. Esta situación ha dejado en desamparo a gran parte de la sociedad; asimismo, demuestran que incluso el país tiene pocos beneficios económicos derivados de la práctica minera, pues la aportación directa al crecimiento económico nacional está por debajo del 1\% y la recaudación fiscal es de 0.35\% (AZAMAR ALONSO, 2018a).

Por otro lado, algunas de las estrategias para fomentar la explotación minera en México y que destacan por haber sido piedras angulares durante el sexenio de Peña Nieto son las de falso consenso, cooptación comunitaria y criminalización de la protesta. Es importante poner atención en ellas, ya que son elementos en los que el próximo gobierno debe intentar eliminar o por lo menos disminuir. A continuación, se mencionan ciertas características de cada una de estas formas de imposición en los proyectos extractivos de nuestro país.

\subsection{Falso consenso}

Esta es desplegada por dos vías: 1) A través del Estado, como proyector de la racionalidad formal de la modernidad y, 2) por medio de las propias compañías mineras interesadas. La legitimidad social; es decir, la ejecución de tácticas específicas para conseguir aprobación ya sea del conjunto de la sociedad, o bien, de la región donde se intenta asentar un nuevo proyecto extractivo. Esta táctica puede describirse de la siguiente manera: las empresas mineras han configurado, a favor de sus intereses, formas sociales de ver, sentir y experimentar la realidad, desde aspectos positivos (empleos, ingresos, etc.) hasta los negativos (afectación social y ambiental) de manera que las personas que luchan por sus derechos pueden ser catalogadas como contrarias al "supuesto" bienestar general.

Como es comprensible, estas formas de ver, sentir y experimentar el mundo rebasan el campo del extractivismo minero, dichas maneras de entender la realidad tienen un ámbito de acción mayor, ligado principalmente a la ideología dominante del "desarrollo”, entendido únicamente como crecimiento económico y expansión masiva del consumo. El consenso social respecto a las prácticas extractivas, la contaminación, la bio-prospección, la tala inmoderada $\mathrm{y}$, un sin número de prácticas empresariales ligadas a la depredación ambiental y humana se relacionan con que prácticamente no se cuestiona la idea dominante del capitalismo: "el crecimiento desenfrenado".

La generación del consenso social y sus tácticas de gubernamentalidad son continuaciones tanto de la colonialidad (POLO BLANCO, 2018) como de las estrategias del poder en el saber (LEFF, 2017); es decir, son reinterpretaciones de la apropiación 
de la naturaleza (ALIMONDA et al, 2002; ALIMONDA et al, 2006; ALIMONDA et al, 2017) y del poder científico moderno sobre otras formas de conocimiento y aprovechamiento de la naturaleza.

La minería utiliza las estrategias más trilladas de legitimidad social auto-asociándose siempre al desarrollo y a la modernización. Mientras está discursividad siga siendo válida, la dicha legitimidad de las prácticas extractivas -aún las más depredadoras-, encontrará masivos partidarios del extractivismo minero, como hoy ocurre en ciertos países latinoamericanos favorecidos con la renta minera 9 .

Durante el sexenio en que gobernó Peña Nieto en México se crearon herramientas de inversión social, como el Fondo para el Desarrollo Regional Sustentable de Estado y Municipios Mineros (Fondo Minero) para mejorar la adopción de megaproyectos en este sector, pues cualquier comunidad que tuviera un gran nivel de operación se supone que se vería beneficiada con los fondos de este mecanismo para invertir en infraestructura y desarrollo.

Uno de los problemas que presenta dicho Fondo es el de su carácter clientelista; además, genera un falso consenso al mantener un discurso de mejora social y económica en tanto se apoye a la industria. Es decir, de esta forma se manipula a la población y se le integra en un proceso de explotación ambiental que es aceptado por las promesas de un posible beneficio económico a futuro.

\subsection{Cooptación comunitaria}

Otra de las maneras de operación del Estado mexicano en los últimos años es la cooptación comunitaria. Esta trata sobre el convencimiento masivo que, al mismo tiempo, retrata el desplazamiento de las tareas estatales por las prácticas empresariales en el contexto neoliberal. La cooptación comunitaria desplegada por las empresas mineras comienza una vez que estas llegan a los territorios aprovechables. Se basa en la creación de promesas de compensación focalizadas, como puede ser: la construcción o apoyo para caminos, escuelas, clínicas, iglesias etc. de forma que las compañías reemplazan al Estado en los aspectos de desarrollo social. Este reemplazo le permite al capital corporativo "controlar de forma más directa a los propios gobernantes, reforzándose con todo esto la jerarquía mundial de poder y los alineamientos, sometimientos y arbitrariedades de las fuerzas neoconservadoras" (GONZÁLEZ CASANOVA, 2002, p. 179).

Esta compensación focalizada -aunque la compensación a menudo sea un insultante resarcimiento- genera, un nuevo régimen de dominación autocrático-clientelar (AZAMAR ALONSO, 2018a) en el que la administración de la compañía minera toma el lugar de mando sobre las autoridades comunales o municipales, quienes a su vez intentan sofocar las resistencias y el poder de los órganos de decisión comunitaria. Este recurso es usado, sobre todo, cuando las empresas comienzan operando en la

9. Naciones como Perú, Bolivia y Chile reciben del sector minero un porcentaje superior a $10 \%$ como aportación para su Producto Interno Bruto. 
ilegalidad, para más tarde, mediante estos mecanismos puedan incidir en las reglas institucionales (DELGADO RAMOS, 2013).

Como expone Garibay (2010, p.176) "la condición clientelar invierte las deudas sociales. El grupo en control de los puestos de autoridad queda en deuda, ya no con la asamblea comunal que los elogió, sino con la corporación minera por aceptarle beneficios". Para este fin, las compañías mineras destinan diversas cantidades de dinero, contabilizadas desde el inicio de los megaproyectos y dosificadas según el grado de conflictividad, control de la población, localización de los factores de riesgo, entre otros.

Otro recurso recurrente es la supuesta firma de contratos de renta de suelo que otorga poderes plenipotenciarios sobre el territorio a las empresas poseedoras de dichos contratos. Bajo el manto del derecho, las compañías mineras eliminan el supuesto de la desposesión y subordinan a la comunidad bajo el condicionamiento del pago de la renta. Esta forma de cooptación comunitaria, entendida como la instauración de un régimen autocrático de dominación fundado en la coerción, impuesto por un poder externo sobre estructuras institucionales y discursivas del espacio social comunitario, termina por afectar en su núcleo a los habitantes y disuelve el tejido social (GARIBAY, 2010).

Estas prácticas, al mismo tiempo que engañan a la población, van generando disciplinamiento de los habitantes ante la desaparición de la presencia del Estado. Las comunidades se ven aisladas y marginadas por las autoridades, por ello tienen que utilizar sus propios recursos para defenderse $\mathrm{y}$ en ocasiones intentar negociar con las empresas sin generar conflicto, ya que son ellos los que están expuestos a riesgos de salud, a pérdida de sus ecosistemas y de la vida misma.
En México existen varios ejemplos notables de cooptación comunitaria, lo que además se ha acentuado en los últimos años. Uno de los más representativos es la creación de una gran clínica por medio de Gold Corp -empresa canadiense- en la comunidad de Mazapil, en el estado de Zacatecas, dicha clínica ha sido entregada al Instituto Mexicano del Seguro Social. Mazapil, se encuentra en los niveles más bajos de desarrollo y en los más altos de marginación en el país, pero también se caracteriza por ser la principal región productora de oro a nivel nacional (OLIVERA VILLA; DE LA FUENTE, 2018).

Aunque existe resistencia ante la actividad minera en el lugar, lo cierto es que actualmente se carece de los medios suficientes para alimentar una gran unidad que pueda derrumbar la fuerza de la compañía, sobre todo cuando esta comunidad requiere infraestructura de servicios sociales básicos, lo que puede influir para disminuir el apoyo entre los pobladores para cuestionar la forma en que se llevan a cabo las actividades de explotación.

\subsection{Criminalización de la protesta y represión}

En este contexto, es común que las empresas mineras generen un clima de inestabilidad social en las regiones donde el conflicto no ha podido solucionarse por la aplicación de las estrategias formales o informales de dominación no explícitamente violentas. Esta táctica juega un papel muy importante en la construcción de la opinión pública en contra del subversivo (NAVARRO, 2012) que se opone al supuesto "desarrollo nacional”. De esta forma se justifica el uso de la violencia legítima del Estado para disminuir las amenazas que afectarían 
el crecimiento económico del país.

En la mayoría de los casos de los grupos de resistencia social en México, estos se enfrentan a un clima amenazante y peligroso que ha cobrado decenas de vidas, sobre todo durante el último sexenio (LEYVA HERNÁNDEZ; GARCÍA BRAVO; CAMPUZANO GODÍNEZ, 2018). Las tácticas del extractivismo minero actual están enfocadas en mantener a la sociedad global y nacional en la indiferencia a través de la lógica de los males necesarios para el desarrollo. Sin embargo, a nivel local las luchas socioambientales contra el extractivismo minero, se enfrentan a todo tipo de mecanismos de contención y a la coacción policial, militar y paramilitar que en algunos casos es explícita y en otros se presenta a través de la promoción de enfrentamientos internos entre comunidades.

$\mathrm{Al}$ respecto, vale la pena mencionar el caso de la Coordinadora Regional de Autoridades Comunitarias - Policía Comunitaria (CRAC-PC) que encabeza la resistencia contra cinco emprendimientos mineros en la región de la Costa de la Montaña en el estado de Guerrero, ya que es ilustrativo el despliegue de las estrategias informales de dominación en un contexto de lucha antiminera.

En este escenario tanto el Estado como los canales de comunicación públicos y privados se aprovechan del clima convulsionado generado por la llegada de las compañías mineras al territorio comunitario en un contexto de militarización de la región y el país. Los poderes mediáticos han justificado la disolución de las Autoridades Comunitarias difamándoles como grupos asociados a la delincuencia organizada. Además, en esta zona las empresas mineras también han aprovechado las divisiones internas que se encontraban latentes en la organización comunitaria para crear un sisma que ha servido de ante sala para la criminalización de la protesta anti-minera y para la penetración de recursos públicos que intentan desarticular el proceso de construcción de autonomía que ha venido generándose desde hace casi dos décadas. Asimismo, en los años en que han resistido, aún con sus divisiones internas, han tenido que soportar los estragos de la violencia paramilitar.

Sin duda, la práctica represiva más violenta que han sufrido es el asesinato de miembros visibles o estratégicos de organizaciones anti-mineras, a menudo simulados en actos de violencia ajenos al contexto de lucha. Además, en el contexto actual de México se pueden observar múltiples casos en los que organizaciones criminales de narcotraficantes actúan como brazo armado de las empresas extractivas que violentan a la población que se opone a estos proyectos de explotación de la naturaleza.

Uno de los casos más notables en la minería es el del asesinato a manos de sicarios -según pesquisas oficiales- del activista Mariano Abarca Roblero quien se manifestaba contra las operaciones de la empresa canadiense Blackfire Exploration Ltd. en Chicomuselo, Chiapas. Así como este se han detectado al menos nueve casos más con el mismo patrón de acción contra dirigentes y activistas contra el extractivismo en esta actividad en México (AZAMAR ALONSO, 2018b).

Este sombrío y dramático panorama de violaciones a derechos humanos y asesinatos es preocupante y no deja de sorprender, aunque en el contexto actual de aseguramiento de los bienes comunes (AZAMAR ALONSO, 2017) parece que se ha vuelto común -para el capital- el aumento de la violencia formal e informal, sobre todo, 
en la periferia del mundo intervenida por las grandes potencias a través de planes e iniciativas que buscan a toda costa recomponer la profunda crisis capitalista que la racionalidad económica moderna no puede resolver por otras vías.

A pesar de las evidentes pruebas de los casos de violencia y despojo que actualmente suceden en el país, el nuevo gobierno nacional aún no ha establecido nuevas estrategias que ayuden a disminuir esta forma de ataque contra la población local que defiende sus derechos ante las megaempresas extractivas, entendiéndolas como procesos de resistencia y lucha contra el saqueo que despliega una riqueza de procesos sociales emergentes por la reapropiación social de la naturaleza.

\section{Conclusiones}

El fenómeno del nuevo auge minero toma lugar en una compleja coyuntura, tanto en el mundo, como a nivel regional y nacional. El aceleramiento del extractivismo está íntimamente ligado a las transformaciones del modelo de acumulación capitalista. Las mutaciones de este proceso en las últimas décadas han reforzado los rasgos depredadores que definen la relación sociedad-naturaleza regida por la racionalidad formal de la modernidad.

Las crisis de sobreacumulación y sobreproducción -a la que se conoce como neoliberalismo- llevan más de cuarenta años; sin embargo, su velocidad de reproducción ha expuesto vertiginosamente las contradicciones más profundas de la racionalidad económica capitalista, arrastrando a las sociedades contemporáneas a una profunda crisis civilizatoria.

Ante este escenario es fundamental diseñar nuevas estrategias que impacten no solo en las prácticas políticas sino en la reestructuración del sistema de reglas de pensamiento y de acción que configuran las instituciones sociales y que otorgan sentido a la organización de la sociedad; es decir, es necesario reconstruir la legitimidad institucional.

Como se ha señalado, la normatividad creada desde un Estado cooptado por grandes empresas -como en el caso de Méxicoes limitada en cuanto al carácter de protección y bienestar social. Asimismo, existe dificultad por parte del Estado mexicano para crear condiciones de cooperación, control y monitoreo de la actividad minera en el país. Además, uno de los grandes problemas es la falta de una figura institucional fuerte que tenga íntima relación con las poblaciones afectadas.

Asimismo, la minería ha provocado notables violaciones a los derechos humanos por la práctica de criminalizar la protesta pacífica, sobre todo durante el último sexenio. Si a esto se le suma que las comunidades donde se realiza esta actividad viven con altos niveles de pobreza, se entiende por qué la explotación de estos recursos juega un papel fundamental en la actualidad.

Por otro lado, la mayoría de los esfuerzos políticos de la administración de Peña Nieto se centraron en crear un punto de apoyo para las empresas mineras, lo que solo trajo mayores perjuicios para la sociedad y la naturaleza. El nuevo gobierno ha manifestado en su plan pre-elección que le daría impulso a este sector (sin explicar adecuadamente de qué forma), aunque existen evidencias de que esto no ha generado ningún beneficio directo a las comunidades donde se realiza esta práctica. No obstante, en la actualidad esto es incierto, pues hay declaraciones confusas sobre 
la forma en que la nueva administración abordará las condiciones actuales y futuras de los megaproyectos mineros.

Actualmente está en discusión la Ley minera, por lo que, si el Estado mexicano pretende apoyar mínimamente a la sociedad y disminuir un poco los impactos sociales, ecológicos y de afectación a la humanidad debe considerar favorecer las reformas a la Ley Minera que se propusieron a finales del año 2018, con la intención de fortalecer los esquemas y controles operativos que vigilan el bienestar de la población.

\section{Referencias}

ABEDRAPO, E. Aspectos institucionales para el desarrollo de megaproyectos de infraestructura de transporte en Latinoamérica. Diálogo regional de política. Argentina: Prohistoria, 2011.

ALIMONDA, H. Introducción: política, utopía, naturaleza. En: ALIMONDA, H. (Comp.) Ecología Política. Naturaleza, Sociedad y Utopía. Buenos Aires: CLACSO, 2002. pp. 7-14.

ALIMONDA, H. (Comp.). Los tormentos de la materia. Aportes para una ecología política latinoamericana. Argentina: CLACSO, 2006.

ALIMONDA, H.; TORO PÉREZ, C.; FACUNDO, M. (Coord.). Ecología Política Latinoamericana. Pensamiento crítico, diferencia latinoamericana y rearticulación epistémica. Buenos Aires: CLACSO, 2017.

AZAMAR ALONSO, A. Megaminería en México: explotación laboral y acumulación de ganancia. México: Editorial ITACA-Universidad Autónoma Metropolitana, 2017.

AZAMAR ALONSO, A. Minería en América Latina y México: problemas y consecuencias. México: Universidad Autónoma Metropolitana, 2018a.

AZAMAR ALONSO, A. Actividad minera en México, en la mira del narcotráfico. El Universal. 2018b Recuperado de https://www.eluniversal. com.mx/articulo/aleida-azamar/nacion/actividadminera-en-mexico-en-la-mira-del-narcotrafico.

BLANCO WELLS, G.; GÜNTHER, G. M.; GUTIÉRREZ, R.; GONZAGA VALENCIA, J. Introducción. Cambio ambiental global y políticas ambientales en América Latina. En: GÜNTHER, G. M.; GUTIÉRREZ, R. (Coord.). La política del ambiente en América Latina. Una aproximación desde el cambio ambiental global. México: CLACSO, 2017.

BURNES, A. El drama de la minería mexicana: del pacto colonial a la globalización contemporánea. Zacatecas: Universidad Autónoma de Zacatecas, Porrúa, 2006.

CAMIMEX (Cámara Minera de México). Informe anual 2012. México: Cámara Minera de México, 2012.

CÁMARA DE DIPUTADOS DEL H. CONGRESO DE LA UNIÓN. Ley Minera. Diario Oficial de la Federación. Ciudad de México, México, 26 junio 1992. CÁRDENAS GRACIA, J. La minería en México: despojo a la nación. Cuestiones Constitucionales, (28), p. 35-74, 2013.

DE LA FUENTE LÓPEZ, A.; OLIVERA VILLA, B. Las actividades extractivas en México: Estado actual. Anuario 2016. México: Fundar, 2017.

DELGADO RAMOS, G. C. Extractivismo minero, conflicto y resistencia social. Realidad Económica, 265, pp. 60-84, 2012.

DELGADO RAMOS, G. C. Costos ecológicos de la minería aurífera a cielo abierto y resistencia social: una lectura desde el proyecto Caballo Blanco en México. Intersecciones. Antropología, (14), pp. 279-294, 2013.

GARIBAY, C. Paisajes de acumulación por desposesión campesina en el México actual. En DELGADO RAMOS, G.C. (Coord.) Ecología Política de la minería en América Latina. México: CEIICHUNAM, 2010. pp. 133-182.

GONZÁlEZ CASANOVA, P. Democracia, liberación y socialismo: tres alternativas en una. Revista OSAL, (8), pp. 175-180, 2002. 
LEFF, E. (2017). Las relaciones de poder del conocimiento en el campo de la Ecología Política: una mirada desde el sur. En ALIMONDA, H. Toro, C.; MARTÍN, F. (Coord.). Ecología Política Latinoamericana. Pensamiento crítico, diferencia latinoamericana y rearticulación epistémica. Buenos Aires: CLACSO, 2002.

LEYVA HERNÁNDEZ, A.; GARCÍA BRAVO, C.; CAMPUZANO GODÍNEZ, M. Informe sobre la situación de las personas defensoras de los derechos humanos ambientales. México, 2017. México: CEMDA, 2018.

LÓPEZ BÁRCENAS, F.; ESLAVA GALICIA, M. El mineral o la vida. La legislación minera en México. México: COAPI - Pez en el Árbol Editorial, 2011.

LÓPEZ, Emiliano; VÉRTIZ, Francisco. Proyectos de desarrollo en América Latina. Extractivismo, capital transnacional y luchas subalternas. En SABLICH, L. (Coord.) Latin American Perspectivas en español y Português: Vol. I. Buscando alternativas políticas y económicas. Buenos Aires: CLACSO, 2017. pp. 119-145

LUXEMBURG0, R. La acumulación del capital. México: Grijalbo, 1967.

MANDEL, E. La acumulación originaria y la industrialización del tercer mundo. En MANDEL, E. Ensayos sobre el neocapitalismo. México: Era, 1971. pp. 153-171.

NAVARRO, M. L. Las luchas socioambientales en México como una expresión del antagonismo entre lo común y el despojo múltiple. OSAL, Observatorio Social de América Latina, 32 (XIII), pp. 149-172, 2012.

OLIVERA VILLA, B. A.; DE LA FUENTE LÓPEZ, A. (Coords.). Anuario 2017. Las actividades extractivas en México: minería e hidrocarburos hacia el fin del sexenio. México: Fundar, 2018.

PALACIO, G. Suelo, subsuelo y vuelo. Los previsibles desafíos ecopolíticos para la región amazónica colombiana. En ALIMONDA, H. (Coord.) La naturaleza colonizada. Ecología política y minería en América Latina. Buenos Aires: CLACSO,
2011. pp. 93-112.

POLO BLANCO, J. Colonialidad múltiple en América Latina: Estructuras de dependencia, relatos de subalternidad. Latin American Research Review, 53 (1), pp. 111-125, 2018.

SECRETARÍA DE ECONOMÍA. Guía de Procedimientos Mineros. México: Secretaría de Economía, 2013.

TETREAULT, D. Resistance to Canadian mining projects in Mexico: lessons from the lifecycle of the San Xavier Mine in San Luis Potosí. Journal of Politica Ecology, 26 (1), pp. 84-104, 2019. 
RESUMEN

México se ha convertido en un país de referencia mundial en cuanto a potencial y facilidades para el desarrollo de megaproyectos en el sector minero. Esto se debe en parte a las múltiples reformas legislativas en materia energética y de dominio eminente de la tierra que se dieron desde la década de los noventa y se consolidaron en el sexenio pasado. En este trabajo se estudian las propuestas legislativas en materia minera, así como la agenda del sector con la intención de valorar los aspectos que influyen en el desarrollo del escenario minero nacional. Asimismo, se muestran diferentes formas de manipulación que el Estado y las empresas han utilizado para que las comunidades accedan a la instalación de proyectos mineros.

\section{PALABRAS CLAVE}

Megaminería. Extractivismo. Legislación. Strategias de manipulación.

\begin{abstract}
Mexico has become a country of global reference in terms of potential and facilities for the development of the mining sector. This is due in part to the multiple legislative reforms on energy and eminent domain of the land that occurred since the nineties and were consolidated in the last six years. In this paper we study the legislative proposals in mining matters, as well as the sector's agenda with the intention of assesing the aspects that influence the development of national mining scenario. Also, different forms of manipulation are shown that the State and the companies have used for the communities to access the installation of mining projects.
\end{abstract}

\section{KEYWORDS}

Mega-mining. Extractivism. Legislation. Manipulation strategies. 